\title{
Inferior Vena Cava Filter Use and Risk of DVT/PE Post Arthroplasty
}

\author{
Daniel R Mesko D0 ${ }^{1 *}$, Nikkole Haines MD ${ }^{1}$, Alex Sadauskas BS ${ }^{2}$ and Scott M Sporer MD ${ }^{1}$ \\ ${ }^{1}$ Department of Orthopaedic Surgery, RUSH University Medical Center, USA \\ ${ }^{2}$ Department of Orthopaedics, Saint Louis University School of Medicine, USA
}

Submission: June 15, 2018; Published: July 10, 2018

*Corresponding author: Daniel R Mesko, Department of Orthopaedic Surgery, RUSH University Medical Center, 1161 W Harrison St Chicago, IL 60612, Tel: (877) 632 6637; Email: dan.mesko@gmail.com

Abstract

Background: Despite anticoagulation use, total joint arthroplasty has a 0.16-1.51\% pulmonary embolism (PE) rate and a 0.1-0.2\% fatal PE rate. The purpose of this study was to describe the post-operative thrombotic events and complications in patients at high-risk in two groups, those who had an IVC filter placed prior to total joint replacement surgery and those who did not.

Methods: Patients from a single surgeon's practice were reviewed between January 1, 2012 to December 31, 2015 that were identified as high-risk for post-operative thrombotic events. Patient demographics, medical history, Charlson Comorbidity Index, filter-related complications, as well as post-operative deep vein thrombosis, pulmonary embolism, bleeding events and hospitalizations were collected retrospectively from the electronic medical records.

Results: Fifty-five patients were identified, thirty-six of whom had a filter placed. Two of these had filter placement and removal on separate occasions for separate arthroplasty surgeries. Of the IVC filters placed, two insertional complications were identified. No filter retrieval complications occurred in the filters that were removed. There were nineteen patients deemed high risk for postoperative thrombotic events that did not undergo filter placement. Of these, there were no cases of pulmonary embolism. One patient was found to have a chronic lower-extremity DVT on post-operative work-up.

Conclusion: In our series, there were two complications related to filter placement. The group of nineteen high risk patients without a filter placed showed no cases of symptomatic PE. Further multicenter study is required to make definitive recommendations on the use of IVC filters in select arthroplasty patients.

Keywords: Inferior Vena Cava Filter; Total Joint Arthroplasty; Pulmonary Embolism; Thrombotic Event

Abbreviations: PE: Pulmonary Embolism; DVT: Deep Vein Thrombosis; TJA: Total Joint Arthroplasty; IVC Filter: Inferior Vena Cava Filter; CCI: Charlson Comorbidity Index; THA: Total Hip Arthroplasty

\section{Introduction}

The use of regional anesthesia, expeditious surgical times, early ambulation, sequential compression devices and anticoagulants have all helped reduce the rate of symptomatic pulmonary embolism (PE) and deep vein thrombosis (DVT) [1]. Despite these improvements, symptomatic PE, including fatal PE, still occurs after joint arthroplasty. PE's following arthroplasty surgery without prophylaxis occur at a rate between $4-10 \%$ with a fatality rate of $0.2-5 \%$ [2,3]. Fatal PE's following total joint arthroplasty (TJA) with more modern techniques and prophylaxis have been found to occur from $0.08-0.2 \%$ [2,3]. While thrombotic events remain relatively uncommon, a projected increase of both primary and revision hip and knee arthroplasty cases to over 4.4 million annually by 2030 represents a potential for over 8,800 PE-related deaths in the same time frame [4].
Utilization of more aggressive anticoagulation has been looked at in depth to manage patients potentially at higher risk for such events; however, this has not demonstrated any reduction in the incidence of fatal PE after total joint arthroplasty [5].

In addition to not reducing fatal $\mathrm{PE}$, potent anticoagulation increases the risks of wound complications, infections, and allcause mortality compared to less aggressive anticoagulation regimens [6]. Furthermore, many fatal PE's occur prior to anticoagulation initiation postoperatively [7]. A prophylactic IVC filter is a supplemental and/or alternative method for prevention of PE that has been investigated more in the bariatric, spine and trauma literature than the arthroplasty literature [8-18]. The use of prophylactic IVC filters in high-risk arthroplasty patients prior to surgery has not been widely utilized. According to current AAOS guidelines, there is a lack of compelling evidence 


\section{Orthopedics and Rheumatology Open Access Journal (OROAJ)}

for or against filter use in patients who have a contraindication to anticoagulation or known residual venous thromboembolic disease [19].

CHEST guidelines recommend against prophylactic IVC filters, even in patients with contraindications to pharmacologic or mechanical prophylaxis, due to low quality evidence supporting their benefit and due to cases of complications during insertion and retrieval [18]. The purpose of this study was to look at the use of prophylactic IVC filters in patients undergoing total joint replacement surgery and to evaluate complication rates related to filter placement/removal as well as post-thrombotic events in these high-risk patients. Our hypothesis is that IVC filters, in high risk patients, show equal or reduced rates of fatal PE compared to a similar group of high risk patients from the same surgeon as well as the current literature rates, with minimal complications during filter placement / retrieval.

\section{Materials and Methods}

After institutional review board study approval was obtained, our digital database was used to identify patients undergoing primary total joint arthroplasty between January 1 , 2012 to December 31, 2015 who were identified by the clearing medical physician as high-risk for thrombotic event. Of the 55 patients identified, an IVC filter was placed prior to undergoing total joint arthroplasty in 36 of these patients. For inclusion, we required chart follow-up for a minimum of 6 weeks postoperatively or until the patient was deceased. Thirty-six patients with thirty-eight IVC filter placements were identified (10 total hips, 21 total knees, 1 simultaneous bilateral total knees and 6 staged bilateral knees). Retrospectively collected data included

Table 1: Demographics.

\begin{tabular}{|c|c|c|c|}
\hline & No Filter & IVC Filter & $P$ value \\
\hline Gender & & & $\mathrm{p}=0.255$ \\
\hline Male & 6 & 18 & \\
\hline Female & 13 & 20 & \\
\hline Age (years) & $70.2+/-7.3$ & $70.8+/-9.3$ & $\mathrm{p}=0.814$ \\
\hline Charlson Comorbidity Index & $3.7+/-1.5$ & $4.3+/-2.6$ & $\mathrm{p}=0.334$ \\
\hline \multicolumn{4}{|l|}{ Procedure } \\
\hline TKA & 13 & 21 & \\
\hline THA & 6 & 10 & \\
\hline Bilateral TKA & 0 & 1 & \\
\hline Staged TKA & 0 & 6 & \\
\hline \multicolumn{4}{|l|}{ Anesthesia } \\
\hline Spinal & 12 & 36 & \\
\hline General & 7 & 2 & \\
\hline Operative Time (minutes) & $90.5+/-18.6$ & $89.8+/-24.1$ & $\mathrm{p}=0.908$ \\
\hline Follow-up (days) & $712.8+/-438.7$ & $863.7+/-522.3$ & $\mathrm{p}=0.284$ \\
\hline \multicolumn{4}{|l|}{ Risk Factors } \\
\hline History of PE & $2^{*}$ & 16 & \\
\hline
\end{tabular}




\section{Orthopedics and Rheumatology Open Access Journal (OROAJ)}



*both with $\mathrm{BMI}>40$; ** 1-Factor 2 gene mutation 1-factor $\mathrm{V}$ mutation, 1-APL antibody, 1- sarcoidosis, 2-afib \& prostate CA, 1-TIA, 1-CVA; ***3-Morbid Obesity, 1-Factor V Leiden, 1-Atrial Fibrillation, 1-Metastatic Cancer \& 1-Subacute Femoral DVT; ****1-Gastric Cancer with Bleeding History.

\section{Results}

In our cohort of 38 IVC filters, there were no documented cases of symptomatic PE following arthroplasty surgery. In all but one patient, chemical anticoagulation was also used. Chemical anticoagulation regimens included Warfarin (26 patients), Rivaroxaban (6 patients), Clopidegrol (1 patient), and aspirin (2 patients). Two patients in this cohort were found to have symptomatic DVT following arthroplasty surgery, one was discovered during the initial admission and the second was identified after discharge and required an additional admission.

Table 2: IVC Filter Details.

\begin{tabular}{|c|c|}
\hline Filter Operative Time (Placement - minutes) & $8.9+/-5$ \\
\hline Filter Operative Time (Retrieval - minutes) & $12.0+/-6.8$ \\
\hline Filter Removal (days) & $120.6+/-95.8$ \\
\hline Filter Placement Complications & \\
\hline Retroperitoneal Bleed & 1 \\
\hline Prolonged Insertional Site Bleed & 1 \\
\hline Filter Retrieval Complications & 0 \\
\hline Filters Removed & 27 \\
\hline Filters Retained & 11 \\
\hline
\end{tabular}

Two patients had filter-related complications. One patient presented to the emergency department one day after filter placement with bleeding from the right internal jugular entry site. This was managed with application of surgical skin glue and same-day discharge home. The second patient developed retroperitoneal hemorrhage one day following filter placement. This was managed with an eight-night admission and a diagnostic angiogram, that was negative for an active extravasation. Due to the hemorrhage, the patient's scheduled total hip arthroplasty (THA) was delayed and, in the interim, all anticoagulants were held. The patient then developed bilateral DVT and PE resulting in an additional 7-night hospitalization. Both patients eventually underwent successful arthroplasty surgery without any further symptomatic thromboembolic events.
Of the filters placed, four were intended as permanent filters, two patients passed away from unrelated causes prior to planned removal, two patients refused removal and one patient's filter was left in place long term due to a history of intracranial hemorrhage and subsequent recommendations against systemic anti-coagulation. Of the twenty-nine remaining filters, 27 (93\%) were successfully removed without complication at an average of $120.7+/-95.8$ days and $2(7 \%)$ were lost to follow-up prior to removal. The average IVC extraction procedure took $12+/$ 6.8 minutes (Table 2). One extraction procedure was aborted initially as a $30-40 \%$ occluding thrombus was discovered within the filter; this filter was removed three months later.

Four patients (11\%) who received an IVC filter died during the follow-up period. No deaths were related to the filter or thromboembolic events. Three deaths were cancer-related, and one was secondary to a hypertensive event. In the group of 19 high risk patients who did not have a filter placed, all were managed with warfarin and enoxaparin. Two patients were worked up for DVT post-op, one of which was found to have a chronic thrombus and the second was found to have post-operative swelling not attributed to a thrombotic event. No documented bleeding events related to patients' systemic anticoagulation were discovered. No patients in this cohort died during the follow-up period.

\section{Discussion}

Table 3: Thromboembolic Events.

\begin{tabular}{|c|c|c|}
\hline $\begin{array}{c}\text { Post-Arthroplasty Thromboembolic } \\
\text { Events }\end{array}$ & No Filter & IVC Filter \\
\hline DVT & $1^{*}$ & 2 \\
\hline PE & 0 & 0 \\
\hline
\end{tabular}

*1-likely chronic.

Prevention of thromboembolic events in patients at highrisk for DVT/PE or with a contraindication to anticoagulation presents a significant challenge. Readmission rates among arthroplasty patients, secondary to a symptomatic DVT/PE, were found by White et al. [20] to be 2.4 times higher in patients 
with a prior history of thromboembolic event (Table 3). Other characteristics such as age greater than 70 years old, female gender, elevated BMI, total knee arthroplasties, increased CCI, presence of DVT, anemia, COPD and even depression have been identified as risk factors for pulmonary embolism [21,22]. The question remains that despite some risk inherent to filter placement, are there specific patients that may benefit from IVC filter placement prior to total joint arthroplasty?

The AAOS guidelines regarding filter use for high-risk patients or those who are not able to be anticoagulated is listed as inconclusive [19]. Even when high risk patients are considered, CHEST guidelines do not recommend prophylactic IVC filters, as PE can still occur, and filters carry a 2-6\% rate of "substantial harm" in their review [18]. Filter placement and removal is not without potential for risk. Issues such as carotid artery puncture, filter migration/tilt, filter breakage with embolism to the heart and lung, need for thoracotomy, post thrombotic syndrome, skin changes and inability to remove the filter due to wall adhesion have all been reported [18]. Filter placement also does not eliminate the possibility of PE, as shown by one of the patients in our study, as any formation and embolization of thrombus proximal to the filter site or in the upper extremities will not be prevented.

Few studies have been published looking specifically at IVC filter placement prophylactically in high risk total joint patients. Vaughn et al., published on 37 patients who had permanent filters placed preoperatively to undergoing total joint arthroplasty. They demonstrated only one case of asymptomatic PE and found no filter related complications at an average follow up of 18.8 months [23]. Emerson et al. [24] also showed no PE diagnoses in a group of 33 patients; however, filter complications, including two vagus nerve injuries, a hemothorax and a placement error above the renal vein, occurred. In another cohort study, Austin et al., looked at filters placed in total joint arthroplasty patients. However, only 18 of these were preoperatively placed, while the remaining 109 filters were placed in reaction to confirmed VTE related events at a mean of 2.7 days post-operatively.

Across the entire cohort, recurrent PE was seen in two patients; it was not clear if these were in the prophylactic IVC filter placement patient group or the reactive placement group. Filter related complications included femoral artery pseudoaneurysm, filter malposition, recurrent or extending DVT in five patients, and 15 patients had a persistent painful lower extremity (post thrombotic syndrome) [25]. As permanent IVC filters have been associated with an increased risk for DVT, the interest in removable filters has grown [26]. Strauss et al. [27] reported on retrievable IVC filters in 58 patients, including 12 arthroplasty patients. Sixty-four percent of the filters were retrieved, all without insertional or retrieval complications. Dhand et al. [28] have published the largest study to date with 109 retrievable filters placed prior to TJA. Their study group had two symptomatic PEs despite filter placement, neither of which were fatal. All but one of the filters were successfully removed. One major filter related complicated included a fracture of the filter leg, which embolized and necessitated a thoracotomy for removal.

Our study demonstrated results similar to prior studies in our filter patients. Overall, two patients (5.3\%) had an adverse event (both were DVT) during the follow-up period. No patients sustained a PE post arthroplasty. Two patients (5.3\%) had a complication related to filter placement, and four patients $(11 \%)$ died of unrelated causes during the follow-up period. One patient had a major complication, a retroperitoneal bleed and subsequent DVT and PE, and second patient had a minor complication. The limitations of our study include the retrospective nature of the study. It is possible a patient presented outside of our system and therefore an adverse event or VTE avoided detection. Complications and adverse events were identified via chart review, therefore non-symptomatic PE/DVT may have been over-looked. Our study is also limited due to the small study numbers over the time investigated. Though small, it is reflective of the more limited volume of highrisk patients and judicious use of preoperative IVC filters in anticipated total joint arthroplasty patients.

\section{Conclusion}

In our high-risk cohort, IVC filters placed prophylactically for total hip and knee arthroplasty showed a relatively low complication rate from filter placement and retrieval, without any cases of postoperative PE's. The control group also demonstrated zero post-operative PE's. As the technology and technique of IVC filter and their placement was evolved, prophylactic use in populations at high risk for thromboembolic events or with a contraindication to anticoagulation after joint arthroplasty should be further investigated through a multicenter study to best identify who may be best served by this technology.

\section{Acknowledgement}

Special Thanks to Roohina Wajid for her assistance with data collection.

\section{Conflict of Interest}

Authors declare that there is no conflict of interest.

\section{References}

1. Salvati EA, Sharrock NE, Westrich G, Potter HG, Valle AGD, et al. (2007) The 2007 ABJS Nicolas Andry Award: three decades of clinical, basic, and applied research on thromboembolic disease after THA: rationale and clinical results of a multimodal prophylaxis protocol. Clin Orthop 459: 246-254.

2. Murray DW, Britton AR, Bulstrode CJ (1996) Thromboprophylaxis and death after total hip replacement. J Bone Joint Surg Br 78: 863-870.

3. Bayley E, Brown S, Bhamber NS, Howard PW (2016) Fatal pulmonary embolism following elective total hip arthroplasty: a 12-year study. Bone Jt J 98-B: 585-588.

4. Kurtz S, Ong K, Lau E, Mowat F, Halpern M (2007) Projections of primary and revision hip and knee arthroplasty in the United States 
from 2005 to 2030. J Bone Joint Surg Am 89: 780-785

5. Poultsides LA, Gonzalez Della Valle A, Memtsoudis SG, Ma Y, Roberts T, et al. (2012) Meta-analysis of cause of death following total joint replacement using different thromboprophylaxis regimens. J Bone Joint Surg Br 94(1): 113-121.

6. Sharrock NE, Gonzalez Della Valle A, Go G, Lyman S, Salvati EA (2008) Potent Anticoagulants are Associated with a Higher All-Cause Mortality Rate After Hip and Knee Arthroplasty. Clin Orthop 466(3): 714-721.

7. Patterson BM, Marchand R, Ranawat C (1989) Complications of heparin therapy after total joint arthroplasty. J Bone Joint Surg Am 71: 1130-1134.

8. Rajasekhar A, Lottenberg R, Lottenberg L, Liu H, Ang D (2011) Pulmonary embolism prophylaxis with inferior vena cava filters in trauma patients: a systematic review using the meta-analysis of observational studies in epidemiology (MOOSE) guidelines. J Thromb Thrombolysis 32(1): 40-46.

9. Carlin AM, Tyburski JG, Wilson RF, Steffes C (2002) Prophylactic and therapeutic inferior vena cava filters to prevent pulmonary emboli in trauma patients. Arch Surg Chic Ill 137: 521-525.

10. Rogers FB, Strindberg G, Shackford SR, Osler TM, Morris CS, et al (1960) Five-year follow-up of prophylactic vena cava filters in highrisk trauma patients. Arch Surg Chic Ill 133: 406-411, Discussion 412.

11. Khansarinia S, Dennis JW, Veldenz HC, Butcher JL, Hartland L (1995) Prophylactic Greenfield filter placement in selected high-risk trauma patients. J Vasc Surg 22: 231-236.

12. Kidane B, Madani AM, Vogt K, Girotti M, Malthaner RA, et al. (2012) The use of prophylactic inferior vena cava filters in trauma patients: a systematic review. Injury 43(5): 542-547.

13. Obeid FN, Bowling WM, Fike JS, Durant JA (2007) Efficacy of prophylactic inferior vena cava filter placement in bariatric surgery. Surg Obes Relat Dis 3(6): 606-608.

14. Rowland SP, Dharmarajah B, Moore HM, Lane TRA, Cousins J, et al. (2015) Inferior vena cava filters for prevention of venous thromboembolism in obese patients undergoing bariatric surgery: a systematic review. Ann Surg 261(1): 35-45.

15. Trigilio-Black CM, Ringley CD, McBride CL, Sorensen VJ, Thompson JS, et al. (2007) Inferior vena cava filter placement for pulmonary embolism risk reduction in super morbidly obese undergoing bariatric surgery. Surg Obes Relat Dis Off J Am Soc Bariatr Surg 3(4): 461-464.

16. Leon L, Rodriguez H, Tawk RG, Ondra SL, Labropoulos N, et al. (2005) The prophylactic use of inferior vena cava filters in patients undergoing high-risk spinal surgery. Ann Vasc Surg 19: 442-447.

This work is licensed under Creative Commons Attribution 4.0 License DOI: 10.19080/OROAJ.2018.12.555836
17. Dazley JM, Wain R, Vellinga RM, Cohen B, Agulnick MA (2012) Prophylactic inferior vena cava filters prevent pulmonary embolisms in high-risk patients undergoing major spinal surgery. J Spinal Disord Tech 25(4): 190-195.

18. Falck-Ytter Y, Francis CW, Johanson NA, Curley C, Dahl OE, et al. (2012) Prevention of VTE in Orthopedic Surgery Patients. Chest 141: e278S - e325S.

19. AAOS Guidelines (2017) preventing venous thromboembolic disease in patients undergoing elective hip and knee arthroplasty. American Academy of Orthopaedic surgeons. USA.

20. White RH, Gettner S, Newman JM, Trauner KB, Romano PS (2000) Predictors of Rehospitalization for Symptomatic Venous Thromboembolism after Total Hip Arthroplasty. N Engl J Med 343:1758-1764.

21. Bohl DD, Maltenfort MG, Huang R, Parvizi J, Lieberman JR, et al. (2016) Development and Validation of a Risk Stratification System for Pulmonary Embolism After Elective Primary Total Joint Arthroplasty. J Arthroplasty 31(9): 187-191.

22. Parvizi J, Huang R, Raphael IJ, Arnold WV, Rothman RH (2014) Symptomatic Pulmonary Embolus After Joint Arthroplasty: Stratification of Risk Factors. Clin Orthop 472(3): 903-912.

23. Vaughn BK, Knezevich S, Lombardi AV, Mallory TH (1989) Use of the Greenfield filter to prevent fatal pulmonary embolism associated with total hip and knee arthroplasty. J Bone Joint Surg Am 71: 1542-1548.

24. Emerson RH, Cross R, Head WC (1991) Prophylactic and early therapeutic use of the greenfield filter in hip and knee joint arthroplasty. J Arthroplasty 6(2): 129-135.

25. Austin MS, Parvizi J, Grossman S, Restrepo C, Klein GR, et al. (2017) The Inferior Vena Cava Filter Is Effective in Preventing Fatal Pulmonary Embolus After Hip and Knee Arthroplasties. J Arthroplasty 22(3): 343348.

26. PREPIC Study Group (2005) Eight-year follow-up of patients with permanent vena cava filters in the prevention of pulmonary embolism: the PREPIC (Prevention du Risque d'Embolie Pulmonaire par Interruption Cave) randomized study. Circulation 112(3): 416-422.

27. Strauss EJ, Egol KA, Alaia M, Hansen D, Bashar M, et al. (2008) The use of retrievable inferior vena cava filters in orthopaedic patients. J Bone Joint Surg Br 90(5): 662-667.

28. Dhand S, Stulberg SD, Puri L, Karp J, Ryu RK, et al. (2015) The Role of Potentially Retrievable Inferior Vena Cava Filters in High-Risk Patients Undergoing Joint Arthroplasty. J Clin Diagn Res JCDR 9(12): TC01TCO3.

\section{Your next submission with Juniper Publishers will reach you the below assets}

- Quality Editorial service

- Swift Peer Review

- Reprints availability

- E-prints Service

- Manuscript Podcast for convenient understanding

- Global attainment for your research

- Manuscript accessibility in different formats

( Pdf, E-pub, Full Text, Audio)

- Unceasing customer service

Track the below URL for one-step submission

https://juniperpublishers.com/online-submission.php 